Universidade Tecnológica Federal do Paraná - UTFPR

Campus Ponta Grossa - Paraná - Brasil

ISSN: 1981-3686/v. 04, n. 01: p. 72-79, 2010

D.O.I.: $10.3895 / \mathrm{S} 1981-36862010000100008$
Revista Brasileira deTecnologia

Agroindustrial

\title{
PRODUÇÃO DE SABONETE TRANSLÚCIDO UTILIZANDO ÓLEO DAS SEMENTES DE MAMÃO HAWAI (Carica papaya) COMO MATÉRIA- PRIMA SAPONIFICÁVEL.
}

\section{TRANSLUCENT SOAP PRODUCTION USING SEED OIL OF HAWAII PAPAYA (Carica papaya) AS RAW SAPONIFIABLE.}

\author{
Darla Cibele Gaia Maciel ${ }^{1}$, Davi do Socorro Barros Brasil ${ }^{2}$, Geraldo Narciso da Rocha Filho ${ }^{3}$, \\ Lênio Jose Guerreiro de Faria ${ }^{4}$ \\ ${ }^{1,2,4}$ Faculdade de Engenharia Química, Instituto de Tecnologia, Universidade Federal do Pará - UFPA - \\ Belém - Brasil davibb@ufpa.br \\ ${ }^{3}$ Faculdade de Química, Instituto de Ciências Exatas e Naturais, Universidade Federal do Pará - UFPA - \\ Belém - Brasil
}

\begin{abstract}
Resumo
O fruto do mamoeiro (Carica papaya L.) é amplamente consumido como alimento em todo o Brasil, porém, somente sua polpa é aproveitada sendo que o restante do fruto casca e sementes são rejeitadas, podendo servir como elementos para estudos de extração de óleos e suas utilizações alternativas. Considerando esse aspecto, foi feito o aproveitamento das sementes do fruto de mamão hawai para obtenção de óleo com a finalidade de empregá-lo na produção de sabonete translúcido. O óleo obtido por extração em Soxhlet foi caracterizado através da determinação dos índices de: saponificação, peróxido, matéria insaponificável e iodo além da análise da composição em ácidos graxos por cromatografia gasosa. $O$ sabonete foi elaborado a partir da adequação de uma formulação típica pela substituição de sebo bovino por óleo de mamão e caracterizado pela determinação dos parâmetros: alcalinidade livre, insolúveis em álcool e pH. Os resultados obtidos foram plenamente satisfatório tanto para o óleo de mamão hawai quanto para o sabonete transparente obtido, indicando que está é uma alternativa viável de reaproveitamento de parte do rejeito gerado pelo consumo desse fruto.
\end{abstract}

Palavras-chave: Sabão transparente; mamão hawai; Carica papaya; reaproveitamento de resíduos.

\section{INTRODUÇÃO}

O mamoeiro (Carica papaya L.) é uma planta nativa da América Tropical, sendo que a primeira referência à sua existência foi feita por volta do ano de 1535, por Ovideo, que informou em carta redigida aos Reis da Espanha ter visto mamoeiros na América Central. No Brasil essa fruteira já era conhecida no ano de 1607, na Bahia (FREITAS, 1979). A partir de 1976/77, a cultura retomou sua importância para o Brasil, principalmente devido à introdução de cultivares havaianos do grupo Solo e de híbridos chineses do grupo Formosa, notadamente nos estados do Pará, Bahia e 
Espírito Santo provocando uma significativa expansão da comercialização do fruto, devido à sua grande aceitação tanto no mercado interno quanto para exportação (MARIN et al., 1995).

Tendo somente sua polpa consumida, o restante do fruto, casca e sementes são rejeitadas, podendo servir como elementos para estudos de extração de óleos e suas utilizações alternativas, tendo como base às características químicas e de acordo com o processo adequado (RENGIFO, 1993).

Nas últimas décadas, o setor de cosméticos obteve um nível de crescimento mundial acima da média em relação a outros produtos industrializados, destacando-se em especial o ramo da higiene pessoal, dentre eles a indústria de sabonetes (CARVALHO, 2000).

Os sabonetes vegetais surgiram para atender uma fatia de mercado mais exigente, mais seleta, que deseja algo mais do que o oferecido pelos sabonetes tradicionais, e, portanto conscientes de que pagarão mais por isso.

Diante dos aspectos mencionados, este trabalho teve como objetivo elaborar sabonete vegetal translúcido, utilizando como matéria saponificável o óleo das sementes de mamão Hawai em substituição ao sebo bovino na formulação, assim como apresentar uma alternativa de reutilização de parte do rejeito gerado deste fruto.

\section{MATERIAL E MÉTODOS}

Obtenção e preparo das sementes de mamão Hawai.

Os frutos maduros de mamão Hawai foram adquiridos na feira do Ver-O-Peso e na CEASA, ambos na cidade de Belém-PA. Estes foram partidos ao meio e as sementes retiradas com auxilio de uma colher. A polpa foi aproveitada para fins alimentícios. As sementes foram, então, lavadas com jatos de água corrente para retirada de restos de polpa, deixando-as escorrer em peneiras e depois foram espalhadas em bandejas, para posterior secagem e extração do óleo.

Secagem das sementes de mamão Hawai.

A secagem foi executada na Usina de Secagem de Produtos Naturais do Laboratório de Engenharia Química da UFPA, em secador de bandejas com circulação de ar quente à $70{ }^{\circ} \mathrm{C}$ até umidade em base seca de $10 \%$ num tempo total de 3,5 horas. As sementes depois de resfriadas foram trituradas em moinho de facas, pesadas e acondicionadas em frascos de vidro âmbar para uso posterior na extração. 


\section{Extração do óleo das sementes de mamão Hawai.}

Foi utilizado o método de extração por solventes em Soxhlet para obtenção do óleo das sementes de mamão Hawai. O solvente hexano foi utilizado para a extração por satisfazer uma série de exigências apropriadas; dissolve com facilidade o óleo sem agir sobre os outros componentes da matéria oleaginosa; possui uma composição homogênea; estreita faixa de temperatura de ebulição e é imiscível em água (MORETTO, FETT, 1998). A extração ocorreu por 8 horas, e, na seqüência o extrato obtido foi concentrado em rotavapor originando um óleo límpido de coloração esverdeada.

\section{Caracterização química do óleo das sementes de mamão hawai.}

Para caracterizar o óleo das sementes foram determinados os seguintes parâmetros: índice de acidez, índice de saponificação, índice de peróxido, índice de matéria insaponificável, índice de iodo (REGULY, 1993) e foi feita a análise da composição em ácidos graxos determinada através de análise por cromatografia gasosa das misturas dos ésteres metílicos preparados de acordo com Khan, Scheinmann (1979). Os ésteres metílicos foram analisados em cromatógrafo a gás CG 14A SHIMADZU acoplado a um integrador processador C-R4A CHROMATOPAC. A determinação da composição em ácidos graxos dos óleos e gorduras foi feita pela quantificação dos picos cromatográficos utilizando-se os padrões estabelecidos dos ácidos graxos.

\section{Metodologia de produção do sabonete translúcido}

Além do óleo das sementes de mamão foi também utilizado óleo de babaçu como matéria prima saponificável, pois, esta segunda matéria prima é rica em ácido láurico, melhorando a qualidade do sabão obtido.

Foi utilizada a proporção de 1:1 entre as quantidades de matérias-primas saponificáveis; a quantidade de soda cáustica teórica foi calculada a partir dos índices de saponificação dos dois óleos utilizados e posteriormente foi determinada a quantidade de lixívia sódica a $29 \%$ necessária. Foram utilizados como agentes de transparência o álcool etílico a $92,8{ }^{\circ} \mathrm{GL}$ e o açúcar comercial, este último também com propriedades de agente de dureza. Os agentes de transparência foram inseridos na formulação na proporção de $1 / 3$ da massa total das matérias primas saponificáveis. $\mathrm{O}$ açúcar foi introduzido na massa reacional na forma de xarope preparado através do aquecimento com água na temperatura aproximada de $80{ }^{\circ} \mathrm{C}$. A quantidade de água utilizada para o preparo do xarope foi de 1/3 da massa de açúcar (INSTITUTO NACIONAL DE TECNOLOGIA, 1983).

A formulação empregada foi adaptada daquela encontrada em literatura especializada (INSTITUTO NACIONAL DE TECNOLOGIA, 1983). O processo de fabricação do sabonete translúcido está demonstrado na figura 1. 


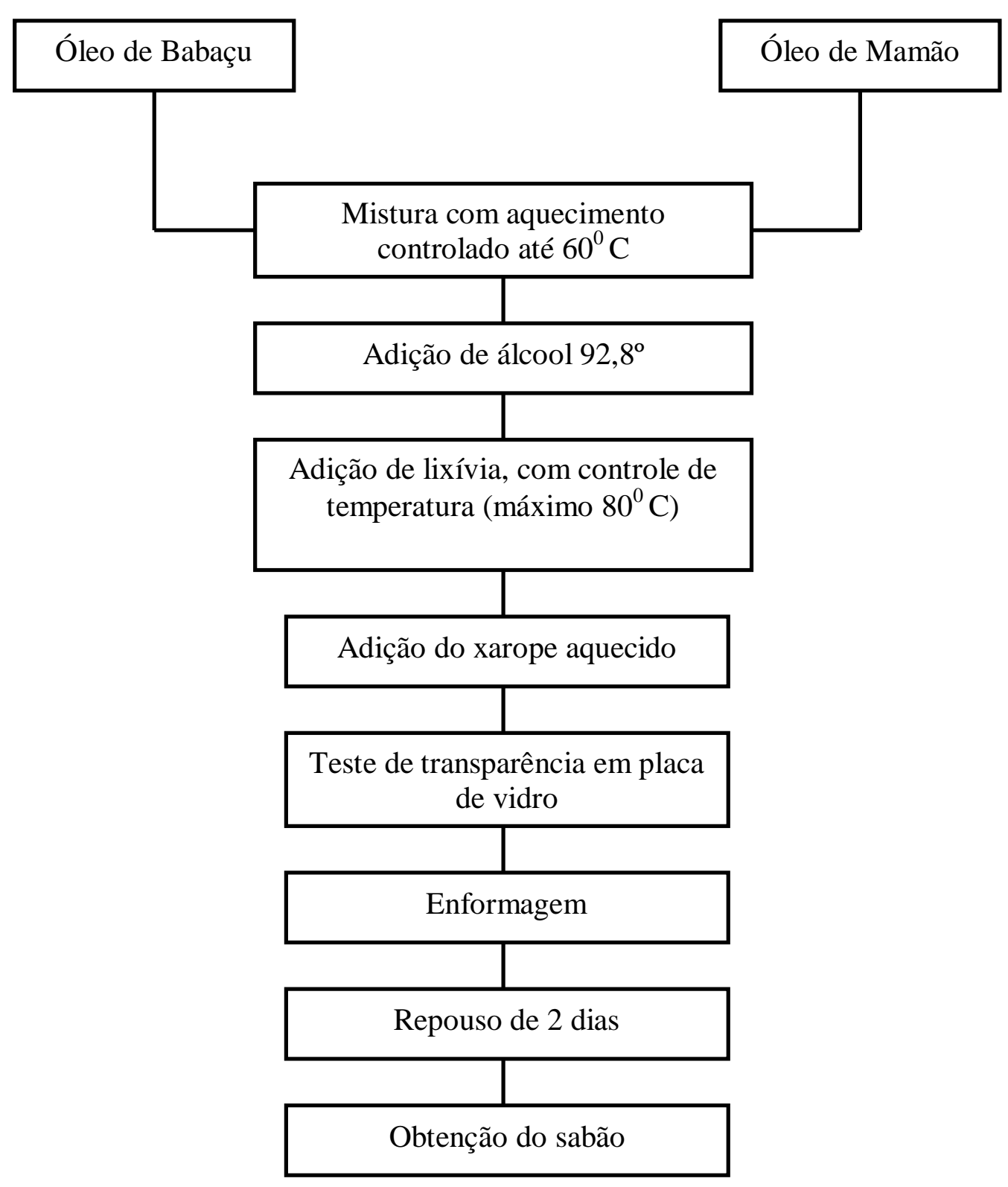

\section{Caracterização do sabonete translúcido}

Para caracterização do sabonete produzido foram determinados os seguintes parâmetros: acidez livre ou alcalinidade livre; insolúveis em álcool e pH (BARROS, 1985).

\section{RESULTADOS E DISCUSSÃO}

\section{Avaliação da secagem das sementes de mamão}

$\mathrm{Na}$ curva de secagem obtida, sob as condições estipuladas, determinou-se o tempo de 3,5 horas (Figura 2) para se obter teor de umidade de 10\% (base seca) nas sementes de mamão Hawai. 
Figura 2 - Curva de secagem das sementes de mamão awai.

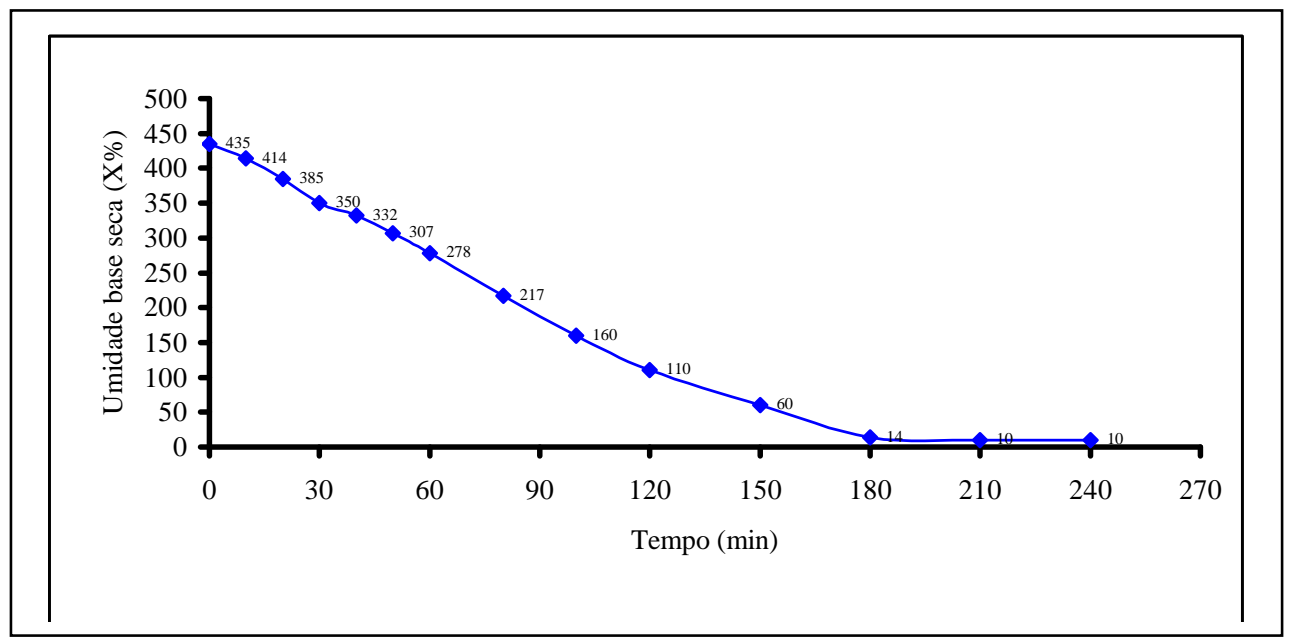

Composição e características químicas do óleo das sementes de mamão

A análise da composição em ácidos graxos do óleo de mamão obtida pela avaliação do cromatograma apresentado na Figura 3 indicou como constituinte majoritário o ácido oléico (18:1) (75,9\%), seguido pelos ácidos palmítico (16:0) (17,9\%) e pelo ácido linoléico (18:2) (4,9\%).

Figura 3 - Cromatograma do óleo das sementes de mamão Hawai.

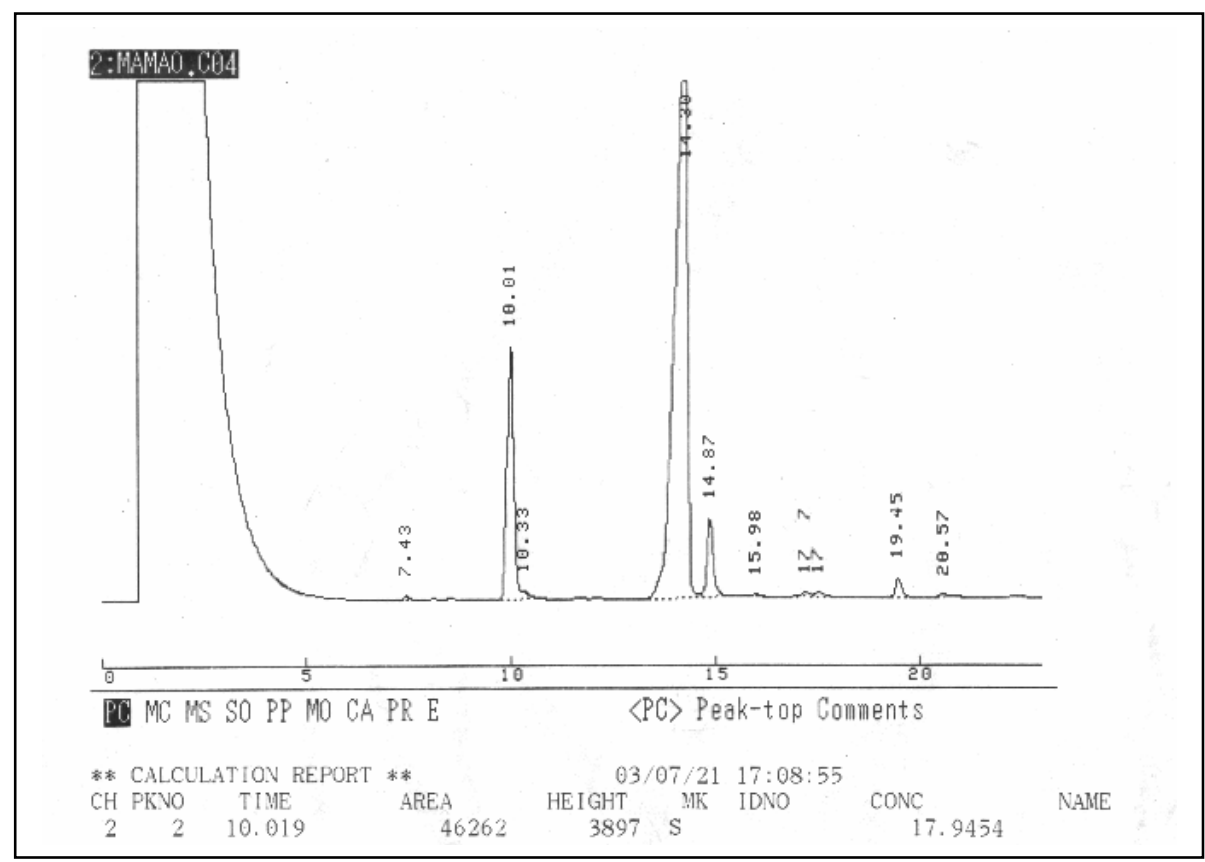

Os valores encontrados para os índices de: acidez $(0,856 \mathrm{mgNaOH} / \mathrm{g})$, matéria insaponificável $(4,4 \%)$, iodo $\left(77,17 \mathrm{gI}_{2} / \mathrm{g}\right)$ e peróxido $(0,00265 \mathrm{meq} / \mathrm{g})$, estão em concordância com dados da literatura (SERRUYA, BENTES, 1980; RENGIFO, 1993) indicando a boa qualidade do óleo obtido das sementes de mamão. O índice de saponificação determinado (194) apresenta coerência com valores encontrados na literatura: 200 (SERRUYA, 1980) e 179 (RENGIFO, 1993), sendo este parâmetro de grande importância para o trabalho, pois o óleo de mamão substituiu o sebo bovino (I.S=190 a 220, REGULY, 1983) na formulação do sabão. O índice de saponificação 
registrado para o óleo de babaçu utilizado na formulação (224) encontra-se ligeiramente abaixo do intervalo (240 a 253) descrito por Reguly (1983).

\title{
Caracterização do sabonete translúcido
}

Os resultados obtidos para as análises de alcalinidade livre $(0,006 \%)$ e de insolúveis em álcool $(0,012 \%)$ encontram-se dentro dos padrões esperados. A Associação Brasileira de Normas Técnicas (ABNT) estabelecia, para sabões de coco a frio, (norma EB-56 de 1954) como limites superiores os valores de 0,02\% e 1\%, para alcalinidade livre e insolúveis em álcool, respectivamente (ASSOCIAÇÃO BRASILEIRA DE NORMAS TÉCNICAS, 1961). Vale ressaltar que esta norma foi cancelada por obsolescência (ASSOCIAÇÃO BRASILEIRA DE NORMAS TÉCNICAS, 2004) e não possui norma substituta. A resolução da diretoria colegiada - RDC № 40, de 5 de junho de 2008 (BRASIL, 2008) estabelece que somente são permitidos para comercialização dos produtos incluídos na categoria sabões, aqueles que apresentem alcalinidade livre máxima expressa em $\mathrm{Na}_{2} \mathrm{O}$ de $1 \%$ p/p. Finalmente, o $\mathrm{pH}$ obtido de 10,48 pode ser considerado adequado para esse tipo de produto.

\section{CONCLUSÕES}

O óleo das sementes de mamão, rico em ácido oléico (18:1), foi saponificado a frio, facilitando o procedimento para obtenção do sabonete e substituiu eficientemente o sebo bovino na formulação utilizada. Apesar do óleo obtido apresentar coloração verde escuro, esta não influenciou no aspecto final do sabonete. A caracterização química do sabonete obtido revela que este foi formulado adequadamente, indicando a viabilidade de utilização do óleo de mamão na obtenção desse tipo de produto.

\begin{abstract}
The papaya fruit (Carica papaya L.) is widely consumed as food in Brazil, however, only the pulp is recovered and the remainder of the fruit, the rind and the seeds are discarded and they can serve as elements for the study of extraction of oils and their alternative uses. Considering this aspect, the seeds of the Hawaii papaya fruit were used for obtaining oil in order to use it in the production of translucent soap. The oil obtained by extraction with hexane was characterized by determining the index: saponification, peroxide, unsaponifiable matter and iodine, besides the analysis of fatty acid composition by gas chromatography. The soap was elaborated according to the suitability of a typical formulation for the replacement of tallow by papaya oil and was characterized by the determination of the parameters: free alkalinity, insoluble in alcohol and $\mathrm{pH}$. The results were fully satisfactory for both Hawaii papaya oil and translucent soap obtained, indicating that this is a viable alternative for the reuse of the waste produced by the consumption of this fruit.
\end{abstract}

Key-words: translucent soap; Hawaii papaya; Carica papaya; use of tailings. 


\section{Referências}

ASSOCIAÇÃO BRASILEIRA DE NORMAS TÉCNICAS (ABNT). Norma EB-56:1954. Sabão comum: especificação brasileira; análise química de sabão comum: método brasileiro, 1961.

ASSOCIAÇÃO BRASILEIRA DE NORMAS TÉCNICAS (ABNT), Declaração de obsolescência de norma brasileira EB-56:1954, 2004. Disponível em: http://www.abnt.org.br/Obsolescencia/EB-56.PDF acessado em 07/10/2009.

BARROS, C. B. Métodos de análise química para produtos de limpeza. São Paulo: IPT, Nº1624, 1985.

BRASIL. Resolução RDC n. 40, de 5 de Junho de 2008. Agência Nacional de Vigilância Sanitária. Regulamento Técnico para Produtos de Limpeza e Afins Harmonizando no âmbito do Mercosul através da Resolução GMC n. 47/07. Diário Oficial da União; Poder Executivo, de 05 de junho de 2008 Brasília, DF. Disponível em: http://elegis.anvisa.gov.br/leisref/public/showAct.php?id=31280\&word= acessada em 9/11/2009.

CARVALHO, M. S. Projeto de implantação de uma indústria de sabonetes vegetais com propriedades fitoterápicas. Trabalho de Conclusão do Curso de Engenharia Química, CT/UFPA, Belém, 2000.

FREITAS, J. M.Q. A cultura do mamão hawai. EMATER-PA, Belém, 1979.

INSTITUTO NACIONAL DE TECNOLOGIA (INT). Curso de Tecnologia de Sabões. São Paulo, Departamento de Química. Universidade de São Paulo, 1983.

KHAN, G. R.; SCHEINMANN, F. Some recent advances in physical methods for analysis and characterisation of polyunsaturated fatty acids. Progress en the Chemistry of Fats and other Lipids, v. 15, p. 343-367, 1978.

MARIN, S. L. D.; GOMES, J. A.; SALGADO, J. S.; MARTINS, D. S.; FULLIN, E. A. Recomendações para a cultura do mamoeiro dos grupos Solo e Formosa no Estado do Espírito Santo. Vitória: EMCAPA (Circular Técnica, 3), 4.ed., 1995.

MORETTO, E.; FETT, R. Tecnologia de óleos e gorduras vegetais na indústria de alimentos. São Paulo: Editora Varela, 1998.

REGULY, J.C. Introdução à analítica e a tecnologia dos carboidratos, lipídios, proteínas e enzimas: um manual de laboratório. Fundação Universidade do Rio Grande, 1983.

RENGIFO, A. A C. Estudo físico-químico do mamão hawai (carica papaya) com maior ênfase nas suas sementes e casca. Dissertação (Mestrado em Química de Produtos Naturais), UFPA, Belém, 1993.

SERRUYA, H.; BENTES, M.H.S. Análise dos óleos das sementes de dois frutos comestíveis cultivados no Pará, mamão (Carica papaya) e maracujá (Passiflora edulis, Passifloracea) In. $1^{\circ}$ e $2^{\circ}$ Encontro de Profissionais da Amazônia, ANAIS, Belém, 1980.

\section{Dados dos autores:}

Nome completo: Darla Cibele Gaia Maciel

Filiação institucional: UFPA

Departamento: Faculdade de Engenharia Química

Função ou cargo ocupado: aluna egressa do curso de Engenharia Química

Titulação: Especialista

\section{Nome completo: Davi do Socorro Barros Brasil}

Filiação institucional: UFPA

Departamento: Faculdade de Engenharia Química 
Função ou cargo ocupado: Professor Ensino Superior

Titulação: Doutor

Endereço: Pass. Boaventura da Silva, 969, bairro Fátima, CEP 66060-470, Belém, Pará. Brasil

Telefones para contato: (91) 32466167; (91) 88568413

e-mail:davibb@ufpa.br

Nome completo: Geraldo Narciso da Rocha Filho

Filiação institucional: UFPA

Departamento: Faculdade de Química

Função ou cargo ocupado: Professor Ensino Superior

Titulação: Doutor

Endereço: Av. 25 de setembro, 1695/1502, Bairro: Marco, 66093-005 Belém-Pará-Brasil.

Telefones para contato: (91) 32018032 ou 99635460

e-mail:narciso@ufpa.br

Nome completo: Lênio Jose Guerreiro de Faria

Filiação institucional: UFPA

Departamento: Faculdade de Engenharia Química

Função ou cargo ocupado: Professor Ensino Superior

Titulação: Doutor

e-mail:lenio@ufpa.br 